\title{
Impact of Hidden Curriculum on Ethical and Aesthetic Values of Sixth Graders in Tafila Directorate of Education
}

\author{
Mohammad Al.qomoul ${ }^{1, *}$ \& Atallah Al.roud ${ }^{1}$ \\ ${ }^{1}$ Department of Curricula and Instruction, Tafila Technical University, Tafila, Jordan \\ *Correspondence: Department of Curricula and Instruction, Tafila Technical University, Jordan. Tel: \\ 962-772-483-000. E-mail: qomoul@yahoo.com
}

Received: January 8, 2017

Accepted: January 22, 2017 Online Published: March 3, 2017

doi:10.5430/jct.v6n1p35

URL: https://doi.org/10.5430/jct.v6n1p35

\begin{abstract}
The present research attempts to investigate the impact of the hidden curriculum on ethical and aesthetic values of sixth graders in Tafila Directorate of education. It also, aims at counting the means and differences between the grades of the positive effects and the grades of the negative effects of both ethical and aesthetic values of the students. However, the researchers use descriptive analytical method to answer the questions of the study. The instruments of the study were actually two questionnaires, one for ethical values and the other for aesthetic values. The sample of the study was 120 students chosen randomly to match the study's objectives. The results reveal noticeable statistical differences $(\alpha=05)$ between the means of the positive values effects and the means of the negative values effects. It also reveals statistical differences ( $\mathrm{F} \alpha=05$ ) in the means of the positive aesthetic values and means of negative aesthetic values in favor of positive values.
\end{abstract}

Keywords: hidden curriculum; ethics; aesthetics; values; sixth graders

\section{Introduction}

The human education is as old as the humanity itself. It is always done by individuals and societies altogether as there are human beings upon the earth. The action of education follows certain imaginations with regard to the targeted persons and the type of life intended to live (Al.Shafee et. al 1996, p. 15). As the education is considered to be one means of finding social values, many educators call for conducting analytical studies to educational values such as: (Saleh, 1994, Aqeel, 1998, Alryyes, 2000, Zyud, 2001 Al.Barakat, and Dawagreh, 2007) and many other studies which generally, focus much on analyzing educational values. However, rarely, we find studies that focus mainly on one particular educational value. So, the researchers in this study attempt to through light on the moral values, since they deal with pertaining the virtual actions. These charitable values are actually, the chain of principles which connect people together. The main objectives of moral values are directed to a supreme humanitarian life, which is needed by all people to stir their consciousness to become noble creatures (Abdu, 1999, p. 23). Aesthetic values have also, its own crucial role in providing humanity with all it needs through its effective impact on the individuals' consciousness. These values, actually, enrich both spirit and soul with higher eminent elements to behave the younger generations (Quoted, 1970, p. 27).

Curricula are several, one of them is called hidden curriculum (Amina, Fayeq, 2007, p. 127). Students are naturally; learn much more from the hidden curriculum since all aims and values of this curriculum are always hidden and unknown. However, most of the researchers focus their attention on the effect of declarative curriculum and its effect on achieving the objectives of the educational process, forgetting the strong impact of the hidden curriculum (Al.mousa, 2000, p. 129). The hidden curriculum has its major part in social education (Kentel, 2009, p. 83) especially, moral and aesthetic values as it revealed in (Tarshes, 2008 and Deutsch, 2004) studies which ensure the effective impact of the hidden curriculum on the students' values and prepare them to be self-reliant and provide them with the needed moral and aesthetic values.

As known to all educators, the hidden curriculum is actually, a new concept in the educational sciences, so more light should be thrown on it, to be more visualized for all teachers and learners (Bumangala, 2010). Who called for the necessity to conduct more researches on hidden curriculum and studying its divertive trends. Educators have to 
create new educational behaviors which promote the positive hidden curriculum. Besides, the research in this type of curricula is an intensive demand for clarifying a new concept in education and instruction. When studying hidden curriculum, we actually, shorten the knowledge and data about it. It is a fact, that hidden curriculum is one means of educational instrument which participate vigorously, in acquiring the students with moral and aesthetic values that remain long with them. Therefore, there is a strong connection between the emergence of hidden curriculum and the prevailed moral and aesthetic values.

\subsection{Purpose of the Study}

The study aimed at:

- Recognizing the nature of the hidden curriculum in our schools.

- Recognizing the impact of the hidden curriculum on the students' moral values.

- Recognizing the impact of the hidden curriculum on the students' aesthetic values.

\subsection{The problem}

In schools, hidden curriculum has its greatest impact on the student's behaviors and then, their values, either positively or negatively. The problem of the study could be restricted to the following questions:

- Is there an impact of the hidden curriculum upon the students' moral and aesthetic values?

- Are there any statistical differences $(\alpha=05)$ between means of students of positive hidden curriculum and means of students of negative hidden curriculum regarding moral values?

- Are there any statistical differences $(\alpha=05)$ between means of students of positive hidden curriculum and means of students of negative hidden curriculum regarding aesthetic values?

\subsection{Significance of the Study}

The importance of hidden curriculum in the teaching-learning process presents its share in various educational experiences, which leaves a strong impact on the students' ethical, social, behavioral, intellectual and spiritual values. Generally, the values themselves are so important for both individuals and societies. A value determines the individual personality and directs his behaviors. It helps much in constructing and forming the individuals' characteristics. However, the present study gains its importance from the fact that the object of the study is rarely handled.

\section{Methodology}

The descriptive analytical method has been adopted, since it is correspondent with the procedures and nature of the present study.

\subsection{Instrument of the Study}

Two questionnaires were constructed by the researchers, one of them for moral values and the other for aesthetic vales. They were distributed to the students to collect their responses about the positive and negative values of the hidden curriculum.

\subsection{The Sample}

The sample of the study has been chosen from the public basic schools in Tafila Directorate of Education in Jordan. Six cooperative schools were chosen purposefully, to match the objective of the study. The schools represent various educational areas in Tafila Directorate of Education. The sixth schools were divided into two groups, three schools represent the positive values of hidden curriculum and the other thee schools represent the negative values of hidden curriculum. A number of 120 students were chosen randomly, from the total number of the six schools, 60 for positive values and 60 for negative values. All the members of the sample are females, although, there are male students in the targeted schools. The objective of the researchers behind this action is only controllable. Table 1 below shows the distribution of the sample of the study. 
Table 1. Presents the Final Distribution of the Sample

\begin{tabular}{ccc}
\hline Schools & Students No & Hidden Curriculum \\
\hline Irwaim & 20 & Positive \\
Hasa & 20 & Positive \\
Eima & 20 & Positive \\
Tafila & 20 & Negative \\
Busara & 20 & Negative \\
Sinfiha & 20 & Negative \\
& 120 & \\
\hline
\end{tabular}

\subsection{Definition of Terms}

- Hidden curriculum: It is the knowledge, values, behaviors, habits and believes that a person, implicitly acquired through teaching-learning processes (Al-fatlawi, 2006, p. 5). It is all the secondary outcomes of the educational process (Jackon, Flulata, 2006, p. 5).

- Ethical values: They are psychological formats that are acquired by individuals through practicing and living social values of the society in which they live (Kashcush and Ismael, 1982, p. 4).

- Aesthetic values: Zahran (1984, p. 184) defines aesthetic values as the values which represent the individuals' interest and their ascending to all beautiful, organized and consistent actualities. The persons who hold this trait are prescribed as artists, creative and aesthetic appreciative.

- Sixth Graders: They are students who finish primary stage in Jordan.

\section{Literature Review}

In this part of the research, the researchers attempt to review some ideas, views and studies which confirm the results of the present study.

Despite the short age of the hidden curriculum, still it is highly, focused on by many researchers and scholars. They all deal with the concept giving it different titles and various definitions, but all of them reach to the same conclusions (Protteli, 1993, p. 344). However, the concept "Hidden Curriculum" is the most common title among all researchers. Dreeben (1986) illustrated that hidden curriculum is all what the students learn through social interaction inside and outside the classroom. Kolberg, (1984) shows a kind of relationship between hidden curriculum and values (Al.mosa, 2003, p. 102). Vallank (1977, p. 50) defined hidden curriculum as non-academic outcomes that focus on achieving religious and social values. Tuma (2008) explains that hidden curriculum is all the knowledge, values and habits that are acquired by the students freely, without any control from the formal curriculum or supervision from the teacher. This kind of curriculum is learnt by observation and imitation of classmates, teachers and surrounding people.

\subsection{Characteristics of Hidden Curriculum}

Hidden curriculum has its own characteristics which are totally different from other known curricula. These characteristics could be summed up in the following points:

- The formal curriculum is always planned previously, by the people who work in the Ministry of Education, whereas, the hidden curriculum is constructed over the nature of educational scenes.

- The outcome of the formal curriculum is normally, positive, since it focused on achieving educational declared purposes. On the other side, we may find that the results of the hidden curriculum could be positive or negative, according to the nature of materials and surrounding people.

- Achieving the purposes of the formal curriculum is compulsory to the people who work in public institutions, whereas, purposes of hidden curriculum is somehow voluntary (McCutcheon, 1988, p. 89). This proposal was advocated by (Ibrahim, 2007) who pointed out that the hidden curriculum is not intended.

- The formal curriculum is somehow, stable; it doesn't change due to the change of educational scenes, while, the hidden curriculum is always changeable, according to the change of time, place and people (Al.khateeb, 2004, p. 25). 


\subsection{Original sources of Hidden Curriculum}

There are two main sources of hidden curriculum:

School sources which is represented by:

a. Teachers: Wiles and Bond (2002, p. 6) illustrated that the teacher's philosophy of teaching is come from his own point of view, since the teacher himself is considered to be the corner stone of the hidden curriculum which reflects his personal, practical and professional character.

b. School syllabus: Regarding its contents and its suitability to the students' needs and interests.

c. Teaching methods: Regarding its variety, modernity and propriety to the students.

d. Teaching aids: Regarding its availability, comprehensiveness and adequacy to the teaching-learning process.

e. Evaluation: Regarding its comprehensiveness and variety.

f. School environment: Regarding prevailing of social and psychological conditions which enable students to accommodate themselves with educational scenes (Fulata, 2006, p. 138).

- Social sources: Represented by the effect of the social, cultural and economic factors and the role of school to foster positive values on the students (Fulata, 2006, p. 138).

\subsection{Components of Hidden Curriculum}

The components of the hidden curriculum could be summed up in the following points:

- Class arrangement and equipment: any effective learning requires arranging the school tables and desks in a circular or squire shape, in order to provide the students with opportunity to see each others and discuss the targeted material freely. The groups of the students shouldn't exceed 4-6 students in each group. A number of studies assured the relationship between the students' achievement and the position of the students in the class (Adams, 1969, Kinarth, 1975, Kelley, 1977). Even the equipment of the class such as: seats and tables have its own effect on both students and teachers. The types of equipment affect much on the students' indirect achievement. Besides, the equipment available to the teachers also, plays a remarkable role on enhancing and pushing them to do their utmost in the teaching-learning process.

- Schooling facilities: any school should have many other facilities which may promote teaching-learning process, such as: libraries, labs, art rooms, theatres, galleries and exhibitions. In these areas, students may gain other experiences, concepts, ideologies and knowledge that are not connected with school syllabus.

- School timetable: school timetable participates effectively in finding hidden curriculum. The significance of timetable is clear in the schools which follow grading system. Walker (1979) viewed graded classes which were initiated in Massachusetts State in 1848 to deal with the students according to their ages, maturity and learning abilities. The students undoubtedly, believe that the time allocated for each subject influences much in their learning. Glatthorn (1987) showed that the supported syllabus reflects supporting sources. He explained that there are some factors which may play crucial role in such syllabuses such as: time allocated for each subject, textbooks and other teaching resources available for learners.

- Teacher's culture and its relation with the prevailed culture. The teacher's culture considered to be one of the main components of the hidden curriculum.

- Textbooks bias: teachers depend highly on the contents of the textbooks, since the students' learning starts with the beginning of the textbook and ends with its ending. Al.musallam (1996) reviewed this by saying, "Teachers are totally, committed to the textbooks, they don't add any extra information except that available in the syllabuses. They only, test the students with the information inserted in the books" (Al.mosa, 2003, p. 107).

- Teachers' scientific background and their performance level: the teachers' scientific background is playing a major role in the teaching-learning process and in achieving its objectives especially, when employing this role effectively. Skilful teacher is normally, distinctive in planning, comprehension and decision making form other fellow teachers. Connel, et. al. (1980) assured that the teacher enters the class reinforced with personal and practical experiences obtained through his work as a teacher. Teachers play an important role in each teaching-learning stage. They plan for all classes, then, they implement their 
plans and finally, they evaluate their work. A teacher, any teacher is the only manager of the teaching-learning process, who also, supervises all the students' activities.

- Teacher's persistence with the students: teacher's personality considered to be most effective element on students' behavior. Students always, imitate their teachers either, positively or negatively. Teachers replace students' parents inside the classroom, so students see them as models to be followed. They gained their teachers' habits, values, attitudes and way of life, reflecting these indirectly, in their daily dispositions. Teachers could help the students to be confident, calm and live peacefully, all the time (Mahmoud and Amin, 2006, ps. 137-138).

\subsection{Educational, Ethical and Aesthetic Values}

Educational values are not only considered to be the core of the educational process, but also, it is one of its greatest objectives and functions. These values are the most important intention for parents, teachers and educational institution altogether (Kanaan, 1995, p. 131).

Gonzales (2004) defined values as thoughts and behaviors which have been acquired by individuals through daily actions either, positively or negatively. These acquired values are finally, affecting and forming their thoughts, attitudes and views. Al.ahmad, Obaid (2007, p. 37) indicated that the values represent hidden curriculum provide a clear profile which determines individuals and societies and lead to what it is socially accepted. Khanaan (1995, p. 39) classified values into nine categories: theoretical, economical, aesthetic, social, political, religious, ethical, personal and spiritual values.

Morals are person's literal character which is connected to values. They are actually, outcomes of the direct interaction between a person and his essence (Qushqush and Ismael, 1984, p. 4). Recently, moral values aimed at reaching its goals through individual behaviors and consciousness. The highly, continuous development which is related normally to technology and its impact on the modern culture bring human societies to a new social net of communication. In this sense, the old traditional values are unable to meet and solve the newly crisis that accompany these rapid developments (Al.kilani, 1992, p. 6).

Aesthetic trend is normally, open or hidden factor, which effectively, improve aesthetic values more than that of other life values. It plays a great role on enhancing human personality through its strong impact on the conscience, where spirit and personality are provided with ascending nobility (Quoted, 1990, p. 27).

Appreciation, consciousness and ability to create are all related to aesthetic recognition as defined by (Abdu, 1999, $\mathrm{p}$. 200). The importance of aesthetic values rises from the fact that humanity is normally, disposed to love nature and its beauty. Even though, Dicart believed that any human being isn't being able to decide fairly on the aesthetic concept, saying that all our sentiments, passivity and passions could be easily controlled, but we normally find ourselves misunderstand these concepts (Abdulmunem, 1987, p. 87). With regard to the previous points, we have to discuss the following items briefly:

a. Aesthetic experiment: it is a mental indication for a high, calm and balanced level of behavior which committed to meet all life affairs without any type of excitability. It aims at bringing peace to hearts and calls for stability to all individuals (Al.shamsi, 2005, p. 75).

b. Aesthetic experience: in this case, any human being finds himself excited with aesthetic vision and lives consciously with this type of experience. The human being here, ties himself directly with the nature of things (Abdu, 1999, p. 187).

c. Aesthetic education: the individual's vision regarding aesthetic concept requires behaving his sense of taste properly in order to be able to decide effectively. However, it is advisable to start educating people on this sense of appreciation from early ages (Abu-ryyan, 1987, p. 107).

\subsection{Attachment between Aesthetics and Ethics}

Sometimes, it is difficult to differentiate between aesthetics and ethics, since the two concepts are highly, interrelated (Nokes, A., 1985, p. 50). However, the contact between aesthetics and ethics could be viewed as follows:

a. Evaluating aesthetics comes out of the aesthetic characteristics and aesthetic experience which enables people to decide freely and logically.

b. Aesthetics are normally, basis and symbols of ethics.

c. Appreciating the beauty of nature leads to noble ethics.

d. Association between aesthetics and ethics establishes ethical aesthetics (Al.shamsi, 2005, p. 68). 


\subsection{Related Studies}

Yusif (1989) conducted a study entitled "Impact of hidden curriculum on the primary stage students' behaviors". The researcher concluded that there are so many acceptable cognitive attitudes and desirable behaviors acquired by the primary stage students through hidden curriculum.

Mahafza (1992) conducted a study entitled "Hidden Curriculum, critical analytical revision for good manners". The researcher drew attention to the school activities as an institution which plays a remarkable role for providing students with values and criteria, unintentionally, through hidden curriculum. He reached to the conclusion that all the knowledge, values and skills acquired by the students through hidden curriculum is of great interest.

Flatter (1995) presented a study entitled "Impact of hidden curriculum on sixth graders' achievement in Macca". The researcher concluded that hidden curriculum had a noticeable effect on the students, especially, in scientific subjects, medium effect in "Hadith" and no effect in history.

Al.mussalam (1996) submitted anther study entitled "Hidden curriculum, its definition, its components and its dangers". The study focused on the role of the hidden curriculum on the social initial process. It started by defining the hidden curriculum then, analyzing its components into six elements: class organization, equipment arrangement, school benefits, study programs, time distribution and teacher's culture and its relation to the prevailed culture. The researcher ended his study by saying that hidden curriculum has its serious dangers, especially, on the younger generations.

Yuksel (2005) pointed out that younger generations should gain the moral values needed by modern society, it is not enough to develop only formal curriculum but also hidden curriculum should be taken into account. Decision makers should also know that the problems cannot be solved with only official curriculum; it should be made clear that official curriculum and hidden curriculum are related to each other. Hidden curriculum cannot be developed without developing formal curriculum (Kohlberg, 1973). Curriculum designers at the Ministries of Education should not think that their responsibility is over when the new curriculum is being used at schools.

Cubukcu (2012) pointed out that students gain two themes: individual benefits and social gains. In terms of individual benefits, students are emphasized that they gained individual cleanliness, loving and keeping animals, hardworking, responsibility and respect of nature, while in terms of social gains, it is concluded that students gained equality, helping, trust and honesty. Moreover, fairness, cooperation and reliability are acquired by students as social gains within the concept of activities supporting the hidden curriculum.

Hashemi (2012) stated that social responsibilities of students in open and closed atmosphere schools has significant differences at level $(\mathrm{p}<0.01)$ and causing the evaluated average. It can be said that students in open atmosphere has an average of (29.27) more than students in closed atmosphere with an average of (26.18). Students in open atmosphere schools have got much more average (51.19) in social moralities relative to students in closed atmosphere schools (48.46).

Azimpour (2015) stated that hidden curriculum significantly determines what the basic sense of value and self-respect in participants, and more influential than any official curriculum in adaptation of teachers and students with educational setting. The teaching materials included in a hidden curriculum are the most important educational contents that students naturally learn at schools.

Sahoo (2015) conducted a study about art and aesthetic values, the summary of the findings of her study could be summed up in the following two points:

- $60 \%$ of the teachers were not giving any attention to art and aesthetic values in the classrooms during teaching.

- $75 \%$ of the students believed that teachers were not motivating to learn subject content through art and aesthetic education.

\section{Procedures of the Study}

The study follows the following steps:

- Defining the problem, its questions, its importance and its objectives.

- Reviewing the literature which tackled ethical, aesthetic values and hidden curriculum.

- Constructing a special questionnaire based on hidden curriculum and ethical values. 
- Constructing another questionnaire for aesthetic values. Table 2 below shows the questionnaire trends.

Table 2. Presets Ethical Values

\begin{tabular}{|c|c|c|c|c|}
\hline Cooperation & Faithfulness & Cleanliness & Honesty & Sincerity \\
\hline \multicolumn{2}{|c|}{ Time management } & Responsibility & Positivism & Arrangement \\
\hline
\end{tabular}

\subsection{Questionnaire Validity}

To achieve validity of the instrument, the researchers distribute it to three university experienced referees specialized in curricula and instruction. The questionnaires were edited finally, according to remarks and comments of the referees.

T-test was employed to calculate the differences between high and low amounts. T-score was found to be $92 \%$ which is significant to be used in the study.

\subsection{Questionnaire Reliability}

Reliability coefficient was calculated after repeating the questionnaire during an interval of three weeks. Coefficient correlation was found to be $84 \%$ which is statistically significant and fulfill the purpose of the present study.

\subsection{Aesthetic Values Questionnaire}

The aim of this questionnaire is to measure aesthetic values for sixth grade students. The questionnaire included the items explained in Table 3 below.

Table 3. Presents Aesthetic Values

\begin{tabular}{ccc}
\hline Aesthetic perception & Creative Personal Composition & $\begin{array}{c}\text { Appreciation of Natural and } \\
\text { Invisible Aesthetic }\end{array}$ \\
\hline Artistic Creation & Nature Love & Supreme Inspiration \\
\hline
\end{tabular}

\subsection{Questionnaire Validity}

The questionnaire was given to three experienced referees to check all the 20 items mentioned on it. After taking the remarks and comments of the referees, the questionnaire was confirmed. T-test was employed to calculate the collected data. T-score was found to be $88 \%$ which is significant to be used in the study.

\subsection{Questionnaire Reliability}

As usual, coefficient correlation was calculated to prove the reliability of the questionnaire. It was found to be $89 \%$ which is significant and suitable for the study.

\section{Discussion of Findings}

- Are there any statistical significant differences $(\alpha=05)$ between the means of sixth grade students who adopt positive hidden curriculum and means of sixth grade students who adopt negative hidden curriculum in moral values?

Table 4 below shows the differences in moral values.

Table 4. Presents Differences of Scores in Ethical Values

\begin{tabular}{cccccc}
\hline Source & $\begin{array}{c}\text { Squire } \\
\text { Total }\end{array}$ & $\begin{array}{c}\text { Freedom } \\
\text { Degree }\end{array}$ & Difference & F. ratio & $\begin{array}{c}\text { Significance } \\
\text { Level }\end{array}$ \\
\hline Groups & 6750 & 1 & 6750 & 8.31 & $(\alpha=05)$ \\
Inter-groups & 1144.815 & 118 & 9.702 & & \\
\hline
\end{tabular}

Table 4 above shows clear statically significant differences between the means of positive hidden curriculum students and the means of negative hidden curriculum students in moral values. The significance is in favor of 
positive hidden curriculum students. The result shows that the hidden curriculum is more effective than that of declared curriculum on the students' ethical values. Hidden curriculum is actually, playing a stronger role than that of declared curriculum. Gordon (1982) assured this fact by saying that hidden curriculum exceeds declared curriculum in providing extra values, experiences and cognitive social attitudes.

Hidden curriculum is distinctive in its various educational parts which provide students with great deal of positive values and honored morals. It urges them to be cooperative, honorable and sincere when work with others. It also, encourages students to take over ethical responsibility in each part of its components, especially, in schools, where educational environment and ethical maturity are confirmed. In this way, hidden curriculum participates indirectly, in building up the students' ethics, especially, when there are efficient teachers, who can facilitate this task through their good deeds and kind words towards students. Some good teachers may work indirectly, to achieve consistence between the students and the society in which they live.

- Are there any statistically significant differences at the level of $(\alpha=05)$ between the means of the students who adopt positive hidden curriculum and the students who adopt negative hidden curriculum in aesthetic values? Table 5 below illustrates the differences between the two groups' scores in aesthetic values.

Table 5. Presents the Differences of Scores in Aesthetic Values

\begin{tabular}{cccccc}
\hline Source & $\begin{array}{c}\text { Squires } \\
\text { Total }\end{array}$ & $\begin{array}{c}\text { Freedom } \\
\text { Degree }\end{array}$ & Difference & F. Ratio & $\begin{array}{c}\text { Significant } \\
\text { Level }\end{array}$ \\
\hline Groups & 6000 & 1 & 6000 & 67.32 & $(\alpha=05)$ \\
Inter-groups & 1043.5 & 118 & 8.84 & & \\
\hline
\end{tabular}

Table 5 above shows statistically significant differences between the means of positive hidden curriculum and the means of negative hidden curriculum in aesthetic values. The difference is in favor of the schools, where positive hidden curriculum is adopted. The results here emphasize the strong impact of the positive hidden curriculum upon the students' aesthetic values positively. The students feel and appreciate aesthetic values and anticipate them freely. The effect of positive hidden curriculum exceeds the effect of the declared curriculum in all aspects of life. So, it encourages students to be creative and pushes them to be able to take correct decisions. This may be attributed to the presence of good professional teachers in schools, where positive hidden curriculum is prevailed. Teachers, who are prescribed with their own aesthetic values, are able to transfer these values to the students through all components of positive hidden curriculum which is clearly represented in the school environment and its equipment.

However, the finding of the present study is highly consistent with the findings of some of the previous studies regarding the impact of the hidden curriculum on students' values especially, moral and aesthetic values e. g. (Yusif, 1989, Mahafza, 1992, Flatter, 1995, Azimpour, 2015, and Safoo, 2015).

\section{Conclusion}

The results of the present study showed that hidden curriculum is not only a collection of uncountable educational accumulations, but also a systematic educational procedure. Hidden curriculum is unlimited in any certain place or time, on the contrary, it could be found in many places and different times. Students, themselves is not the only factor of finding hidden curriculum, hidden curriculums are accompanying us all the time, everywhere and in every activity we do. Finally, we can say that hidden curriculum has a noticeable impact on the students' ethical and aesthetic values, either, positively or negatively.

\section{Recommendations}

In the light of the finding of the present study, the researchers recommend the following:

- Necessity of training the newly appointed teachers about effects and dangers of hidden curriculum on the students.

- Planning training programs for both curriculum designers and teachers about hidden curriculum.

- Conducting other experimental studies which could uncover mysterious parts of such curriculums.

- Conducting more other studies that focus on the relations between hidden curriculums and other educational values. 
- Studying the effects of hidden curriculum on other lower or higher grade students in Jordan.

\section{References}

Abdu, M. (1999). Ethics Psychology, Madbuli Bookshop (2 ${ }^{\text {nd }}$. Ed.).Cairo, Egypt.

Abdulmunem, R. (1987). Aesthetic Values, Studies in Arts and Aesthetics, Dar Almarifeh Al.jamieh, Cairo, Egypt.

Abu Rayan, M. (1987). Aesthetics Philosophy and Establishing of Aesthetic Arts, Dar Al.marifeh Al.jamieh, Cairo, Egypt.

Al.ahmad, A., \& Obaid A. (1997). Evaluating Islamic Ethical Values for Students of Faculty of Education in Kuwait, Journal of Faculty of Arts, 1(57), 37-42.

Al.fatlawi. S., \& Hilali, A. (2006). Teaching Syllabus and Intentional Ideology "Theory and Practice". Dar Al.shorouq, Amman, Jordan.

Ali, B., \& Dawagreh, N. (2007). Educational Values that should be Implemented in Syllabuses of Primary Stage Students. Journal of Educational Psychological Sciences, 8(4), 34-51.

Al.khateeb, M. (2004). Worksheet entitled: "Hidden Curriculum and Declared Curriculum," (Symposium). Al.rhiyad, Kingdom of Saudia Araibia.

Al.kilani, M. (1992). New Trends in Ethical Education, Dar Al.bashir ( $1^{\text {st }}$ ed.). Amman, Jordan.

Al.mosa, A. (1998). Hidden Curriculum, its Onset, Concept, Psychology, Components and Dangers. Um El.qura Journal, 12(1), 107-123.

Almusallam, B. (1998). Hidden Curriculum, its Definition, its Components and its Dangers, Kuwait. Educational Journal, 22(88), 61-84.

Al.rayes, A. A. (2000). Values Implemented in High Grades of Primary Stage in Saudia Arabia, M.A. Thesis, Faculty of Education, King Saud University.

Al.saleh, K. (1994). Analytical Comparative Study for Educational National Syllabuses of Preparatory Stage in Syria, M. A. Thesis, Damascus University.

Al.shafee, et. al. (1996). School Syllabus, New Perspective, King Saud University press, Al.rhiyad, Saudia Arabia.

Al.shamsi, K. (2005). Ethical and Aesthetic Values in Arabian Gulf Education, Dar Atlas (1 $1^{\text {st }}$ ed.). Cairo, Egypt.

Amin, E. and Faiq, N. (2007). Hidden Curriculum and its Relation with Social Skills and Islamic Ethics for Nursing Children, Journal of Reading Knowledge, 2(35), 127-138.

Anox, A. (1985). Aesthetic Theories, (Kant, Heigl Shopenhouer), Bahsoon Cultral Publication, Translation of Mohammad Shafiq Shata, Beirut, Lebanon.

Aqeel, M. (1998). Availability Level of Values in Social Syllabuses Textbooks for Primary Stage, M. A. Thesis, King Saud University, Alrhiyad, Saudia Arabia.

Azimpour, E. (2015). Hidden Curriculum. World Essay Journal, 3(1), 18-21.

Cbukku, Z. (2012). Effect of Hidden Curriculum on Character Education Process of Primary School Students. Educational Sciences: Theory and Practice, 12(2), 1526-1536.

Darren T. (2008). How College Physics Courses Implicitly Influence Student Beliefs, Physics Honor Thesis, University of Colorado at Boulder.

Deutsch, N. (2004). Hidden Curriculum Paper, University of 54-58, Second Conference of the International Society for Scholarship of Teaching and Learning (Vancouver B. C., 14-16, October, 2005).

Fulata, I. (1995). Hidden Curriculum and Its Impact on the Achievement of Sixth Graders in Makka. Assyut University Journal, 5(2), 138-149.

Fulata, I. (2006). Hidden Curriculum, its Role in Sustaining Educational Process, Academic Lecture during Activities of Saudi Society for Curriculum and Educational Supervision, Holy Makka.

Gonzales, M. (2007). The Values Adolescents Aspire for their Children Social Indicators Research. Retrieved from //wwweric.ed.gov/

Gushu, I., \& Ismael, N. (1982). Ethical Values Questionnaire, Anglo Bookshop, Cairo, Egypt. 
- $\quad$ Hashemi, A. (2012). The Role of Hidden Curriculum on Social Education of High School Students. Journal of Life Science Biomedicine, 2(5), 255-259.

Ibrahim, S. (2007). Nursery Child Psychology between Curriculum and Learning Theories, Dar Al.fikr Al.arabi (1 ${ }^{\text {st }}$ ed.). Cairo, Egypt.

Kentli, F. D. (2009). Comparison between Theories of Hidden Curriculum. European Journal of Educational Sciences, 20(2), 105-114.

Khanaan, A. (1995). Child Literature and Educational Values. Dar Al.fikr, for Publishing, $4^{\text {th. }}$ Edition, Cairo, Egypt.

Kohlberg, L. (1973). Moral Development and the New Social Studies. Social Education, 2(37), 369-375.

Mahafza, S. (1992). A Hidden Curriculum, Analytical Critical Revision for Literatures. Social Affairs Journal, 10(35), 23-38.

McCutcheon, G. M. (1988). Curriculum and the Work of Teachers, appears in Apple George Michael and Bayer (eds). Curriculum, Problems, Politics, and Possibilities, Oxford University Press, New York.

Quoted A. G. (1970). Objectivity and Values in the Judgment of Aesthetics. British Journal of Aesthetics, 10(1), 52-61.

Protelli, J. P. (1993). Exposing Hidden Curriculum Studies. Journal of Social Studies, 3(34), 344-356.

Rita B. (2010). Civic Education, Hidden Curriculum, $3^{\text {rd }}$. National Conference on Education for Social Studies Supervisors, (Con-Cess), Philippine Normal University.

Sahoo S. (2015). Implementation of Art and Aesthetic Value in Curriculum Transaction among Secondary School Students: An Analysis. International Journal of Humanities and Social Science Studies, 11(1), 296-304.

Tuma, R. (2008). Contemporary School Syllabus, Dar El.maseera, (1 ${ }^{\text {st }}$ ed.). Amman, Jordan.

Vallanc, E. (1977). Hidden Curriculum: An Interoperation of the Language of Justification in Nineteenth Century Education Reform. In Bellack, A. and Kilebard, H. M. (eds.), Curriculum and Evaluation, Los Angelos, CA: MC: McCutchan Publishing.

Willes, L., \& Bondi, J. (2002). Curriculum Development: A Guide to Practice (6 ${ }^{\text {th }}$ ed.), Boston: Person, University of Phoenix.

Yuksel S. (2005). Kohlberg and Hidden Curriculum in Moral Education: An Opportunity for Students' Acquisition of Moral Values in Turkish Primary Educational Curriculum. Educational Sciences: Theory and Practice, 5(2), 329-338.

Yousof, M. (1989). Impact of Hidden Curriculum on Basic Stage Students' Behaviors, Ph. D. Thesis, Hulwan University, Egypt.

Zahran, H. (1984). Social Psychology, Alam El.kotob, (5 ${ }^{\text {th }}$ Ed.). Beirut, Lebanon.

Zyud, Z. (2001). Educational Values Implemented in Human Science Syllabuses for Preparatory Stage in Syria, M.A. Thesis, Damascus University, Syria. 